\title{
Midregional Proadrenomedullin Can Reflect the Accumulation of Visceral Adipose Tissue-A Key to Explaining the Obesity Paradox
}

\author{
Teruhide Koyama * ${ }^{(\mathbb{D}}$, Nagato Kuriyama and Ritei Uehara \\ Department of Epidemiology for Community Health and Medicine, Kyoto Prefectural University of Medicine, \\ Kyoto 602-8566, Japan; nkuriyam@koto.kpu-m.ac.jp (N.K.); ruehara@koto.kpu-m.ac.jp (R.U.) \\ * Correspondence: tkoyama@koto.kpu-m.ac.jp
}

Received: 12 May 2020; Accepted: 1 June 2020; Published: 3 June 2020

check for updates

\begin{abstract}
Background: The aim of this study was to investigate whether plasma midregional proadrenomedullin (MR-proADM) reflected body composition, such as body mass index (BMI), visceral adipose tissue (VAT), subcutaneous adipose tissue (SAT), VAT/SAT ratio, body fat mass (BFM), and skeletal muscle mass (SMM). Methods: A total of 2244 individuals (727 men and 1517 women) were included in the study. Multiple regression analysis was performed to assess the combined influence of variables: age, daily alcohol consumption, Brinkman index, sleeping time, metabolic equivalents, anamnesis for hypertension, dyslipidemia, diabetes, and body composition of MR-proADM, by using a stepwise forward selection method. Results: MR-proADM was significantly related to all anthropometric indices (BMI, VAT, SAT, VAT/SAT ratio, BFM, and SMM) in men and women. On the basis of a stepwise forward selection method, VAT (men: beta $=0.184, p<0.001$, women: beta $=0.203, p<0.001$ ) and BFM (beta $=0.181, p<0.001$ ) in women, were found to be significantly associated with MR-proADM. Conclusion: This study suggests that plasma MR-proADM concentration is a more reliable indicator of VAT for fat distribution, and thus, MR-proADM may help better understand the obesity paradox. Changes in circulating levels of MR-proADM could possibly reflect changes in body composition, endocrine, and metabolic milieu.
\end{abstract}

Keywords: visceral adipose tissue; body mass index; obesity paradox; MR-proADM

\section{Introduction}

Obesity is a complex multifactorial disease. It adversely affects nearly all physiological functions of the body and constitutes a significant public health threat [1-3]. Overweight and obesity rates have increased considerably during the past 35 years. Currently, more than one-third of the world's population is classified as overweight or obese [4]. The body mass index (BMI) is a simple metric used to indicate overall body fatness. However, a phenomenon known as the "obesity paradox" occurs when a population with normal BMI possibly has a higher risk of mortality than a population with obese BMI $[5,6]$. In general, studies have shown that the distribution of body fat, and not the mass of body fat, is the key to explaining the obesity paradox [6]. Knowledge of the changes in body composition and fat distribution may help to understand the cause of obesity [7].

Adrenomedullin (ADM) is a vasoactive peptide identified in human pheochromocytoma [8]. ADM is secreted from various organs and tissues, and involved in several physiological functions $[9,10]$. ADM is also known as adipokine [11]. Previous studies also reported that the expression of ADM is augmented in the visceral adipose tissue of obese individuals than in nonobese individuals [12,13]. Plasma ADM levels were also found to be higher in obese patients than in controls, suggesting the active production and secretion of ADM from human adipose tissue. ADM was found to be positively 
correlated with BMI in obese participants [14], and increased ADM levels predicted a faster increase in BMI and waist circumference [15]. In sum, ADM may be a key molecule to understand body composition and fat distribution. However, to our knowledge the relationship of ADM with fat and lean tissue mass has not been studied and may require further investigation. Although reliable measurement of plasma ADM levels is difficult because of its short half-life of $22 \mathrm{~min}$ [16], the precursor molecule of ADM, midregional proADM (MR-proADM), has a higher stability, which allows it to be reliably measured as a surrogate biomarker for ADM [17]. Thus, to clarify whether plasma MR-proADM is representative of body composition and fat distribution, we investigated the relationship between MR-proADM and anthropometric indices, such as BMI, visceral adipose tissue (VAT), subcutaneous adipose tissue (SAT), VAT/SAT ratio, body fat mass, and skeletal muscle mass.

\section{Materials and Methods}

\subsection{Participants}

The Japan Multi-Institutional Collaborative Cohort Study was launched in 2005 to investigate the gene-environment interactions of lifestyle-related diseases [18]. This study included individuals who were enrolled in the Japan Multi-Institutional Collaborative Cohort Study's second survey in the Kyoto area from 2013-2017 [19]. A total of 3913 participants were eligible. All subjects underwent routine health check-ups. Among the 3913 participants, 1669 were excluded because of insufficient laboratory data. After these exclusions, 2244 individuals (727 men and 1517 women) were eligible.

The study was approved by the Institutional Ethics Committee of the Kyoto Prefectural University of Medicine (approval number: RBMR-E-36-8 at 2013) and was conducted in accordance with the principles of the Declaration of Helsinki. All participants provided written informed consent before participation.

\subsection{Clinical and Biochemical Analysis}

The following lifestyle and medical information, which was obtained through self-administered questionnaires, was evaluated: alcohol consumption (ethanol/day), Brinkman index (assessed as the number of cigarettes smoked per day $\times$ total number of years smoked), sleeping time, current medication use, and physical activity (assessed as metabolic equivalents (METs)) [20] for daily and leisure activities. The alcoholic content of each type of beverage was calculated; the alcohol consumption was determined by calculating the number of drinks per day, and subsequently, this amount was converted into the Japanese sake unit, "gou" (180 mL), which is equivalent to $23 \mathrm{~g}$ of ethanol. In addition, anthropometric data obtained from health check-ups were collected. Waist circumstance (WC) was measured at the umbilical level during minimal respiration in a standing position. BMI was calculated as weight divided by the square of height $\left(\mathrm{kg} / \mathrm{m}^{2}\right)$.

VAT and SAT were measured using a dual bioelectrical impedance analyzer (DUALSCAN, Omron Healthcare Co. Ltd., Kyoto, Japan). The brachial-ankle pulse wave velocity (baPWV), which is used to evaluate arterial stiffness, was measured with a volume-plethysmographic apparatus (BP-203RPE II form PWV/ABI, Omron Healthcare Co. Ltd., Kyoto, Japan). We simultaneously measured baPWV on both the right and left sides, and the average of the two values for each individual supplied the population data for statistical analysis. Body composition was examined by bioelectrical impedance analysis to measure skeletal muscle mass. Model HBF-375, Omron Healthcare Co., Ltd. Kyoto, Japan, was used to measure the entire body for body fat mass (BFM) and skeletal muscle mass (SMM) [21]. Medication histories were assessed using self-administered questionnaires. Hypertension was defined as a systolic/diastolic blood pressure (SBP/DBP) $\geq 140 / 90 \mathrm{mmHg}$ and/or current use of medication for hypertension. Dyslipidemia was defined as low-density lipoprotein cholesterol (LDL-C) $\geq 140$ $\mathrm{mg} \mathrm{dL}^{-1}$ and/or high-density lipoprotein cholesterol (HDL-C) $<40 \mathrm{mg} \mathrm{dL}^{-1}$ and/or current use of medication for dyslipidemia. Diabetes was defined as a glycated hemoglobin ( $\mathrm{HbA} 1 \mathrm{c})$ level $\geq 6.5 \%$ and/or blood sugar (BS) $\geq 126$ and/or current use of diabetic medication. 
MR-proADM plasma concentrations were measured using an automated KRYPTOR analyzer (ThermoFisher Scientific, Germany), with a time-resolved amplified cryptate emission (TRACE) technology assay (Thermo Fisher Diagnostics K.K., Japan), according to the manufacturer's instructions [17].

\subsection{Statistical Analysis}

Continuous variables are expressed as means \pm standard deviation (SD) and categorical data are expressed as sums and percentages. Intergroup comparisons were performed using Welch's t-tests for continuous variables and Fisher's exact tests for categorical variables. Spearman's rank correlation analysis was performed to assess the relationship between MR-proADM and other variables, including body composition. Multivariate linear regression analysis was used to test associations between MR-proADM and anthropometric indices as represented by the beta coefficient adjusted for age (continuous), daily alcohol consumption, Brinkman index, sleeping time, METs, anamnesis for hypertension, dyslipidemia, diabetes, and body composition. Multiple regression analysis was performed to assess the combined influence of variables on MR-proADM and avoid multicollinearity using a stepwise forward selection method. All statistical analyses were performed using JMP 13 software (SAS Institute Inc., Cary, NC, USA), and $p<0.05$ was considered statistically significant.

\section{Results}

A total of 2244 participants were divided into two groups according to sex. The anthropometric measurements and participant characteristics used in this study are shown in Table 1 . The mean age was $59.7 \pm 10.3$ years in men and $57.1 \pm 9.92$ years in women. The MR-proADM level differed significantly by sex, $0.467 \pm 0.099 \mathrm{nmol} / \mathrm{L}$ in men versus $0.412 \pm 0.082 \mathrm{nmol} / \mathrm{L}$ in women $(p<0.001)$. The SMM and METs values showed no significant difference between the populations of men and women.

Table 1. Characteristics of participants according to sex.

\begin{tabular}{cccccc}
\hline & \multicolumn{2}{c}{ Men } & \multicolumn{2}{c}{ Women } & \\
\cline { 2 - 5 } & \multicolumn{2}{c}{$n=\mathbf{7 2 7}$} & $\boldsymbol{n}=\mathbf{1 5 1 7}$ & \\
\cline { 2 - 5 } & Mean & SD & Mean & SD & $p$-Value \\
\hline Age (years) & 59.7 & 10.3 & 57.1 & 9.92 & $<0.001$ \\
BMI (kg/m $\left.{ }^{2}\right)$ & 23.5 & 2.98 & 21.6 & 3.18 & $<0.001$ \\
VAT $\left(\mathrm{cm}^{2}\right)$ & 79.9 & 36.0 & 51.3 & 26.6 & $<0.001$ \\
SAT (cm $\left.{ }^{2}\right)$ & 145 & 50.9 & 130 & 66.4 & $<0.001$ \\
VAT/SAT ratio & 0.552 & 0.187 & 0.427 & 0.182 & $<0.001$ \\
BFM (\%) & 23.6 & 4.38 & 30.36 & 4.69 & $<0.001$ \\
SMM (\%) & 30.1 & 2.28 & 24.94 & 6.24 & 0.300 \\
METs (hours/day) & 14.8 & 11.0 & 15.4 & 10.4 & 0.248 \\
Brinkman index & 513 & 557 & 69 & 186 & $<0.001$ \\
Alcohol (g/day) & 22.5 & 28.1 & 6.63 & 13.3 & $<0.001$ \\
Sleep time (hours) & 6.48 & 1.03 & 6.37 & 1.00 & 0.016 \\
MR-proADM (nmol/L) & 0.467 & 0.099 & 0.412 & 0.082 & $<0.001$ \\
& $n$ & $\%$ & $\mathrm{n}$ & $\%$ & \\
\hline Hypertension & 364 & 50.1 & 440 & 29.0 & $<0.001$ \\
Dyslipidemia & 322 & 44.3 & 675 & 44.5 & 0.482 \\
Diabetes & 74 & 10.2 & 49 & 3.2 & $<0.001$ \\
\hline
\end{tabular}

Note: $p$-values were determined using Welch's $t$ test or Fisher's exact tests.

Correlations between MR-proADM and body composition are given in Table 2. In men, MR-proADM was found to be significantly correlated with all indices: BMI (coefficient $=0.130$ ), VAT (coefficient $=0.277)$, SAT (coefficient $=0.161)$, VAT/SAT ratio (coefficient $=0.225)$, BFM (coefficient $=0.336$ ), and SMM (coefficient $=-0.485$ ). In women, MR-proADM was found to be 
significantly correlated with BMI (coefficient $=0.304)$, VAT (coefficient $=0.365)$, SAT (coefficient $=0.333$ ), VAT/SAT ratio $($ coefficient $=0.062)$, BFM $($ coefficient $=0.435)$, and SMM $($ coefficient $=-0.413)$.

Table 2. Correlations between midregional proadrenomedullin (MR-proADM) and anthropometric indices.

\begin{tabular}{ccccc}
\hline & \multicolumn{2}{c}{ Men } & \multicolumn{2}{c}{ Women } \\
\cline { 2 - 5 } & Coefficient & $\boldsymbol{p}$-Value & Coefficient & $\boldsymbol{p}$-Value \\
\hline BMI & 0.130 & $<0.001$ & 0.304 & $<0.001$ \\
VAT & 0.277 & $<0.001$ & 0.365 & $<0.001$ \\
SAT & 0.161 & $<0.001$ & 0.333 & $<0.001$ \\
VAT/SAT ratio & 0.225 & $<0.001$ & 0.062 & 0.015 \\
BFM & 0.336 & $<0.001$ & 0.435 & $<0.001$ \\
SMM & -0.485 & $<0.001$ & -0.413 & $<0.001$ \\
\hline
\end{tabular}

In multivariable logistic regression, MR-proADM was significantly correlated with age (men: beta $=0.357, p<0.001$, women: beta $=0.314, p<0.001$ ), hypertension (men: beta $=0.081, p=0.020$, women: beta $=0.086, p<0.001$ ), daily alcohol consumption (men: beta $=0.124, p<0.001$, women: beta $=0.098, p<0.001$ ), and VAT (women: beta $=0.173, p=0.003$ ). These values are shown in Table 3 . On the basis of a stepwise forward selection method, VAT (men: beta $=0.184, p<0.001$, women: beta $=0.203, p<0.001$ ) and BFM (beta $=0.181, p<0.001$ ) in women were found to be significantly associated with MR-proADM.

Table 3. Comparison of the association of MR-proADM with anthropometric measures.

\begin{tabular}{|c|c|c|c|c|c|c|c|c|}
\hline & \multicolumn{4}{|c|}{ Men } & \multicolumn{4}{|c|}{ Women } \\
\hline & \multicolumn{6}{|c|}{ Stepwise } & \multicolumn{2}{|c|}{ Stepwise } \\
\hline & Beta & $p$-Value & Beta & $p$-Value & Beta & $p$-Value & Beta & $p$-Value \\
\hline Age & 0.357 & $<0.001$ & 0.415 & $<0.001$ & 0.314 & $<0.001$ & 0.278 & $<0.001$ \\
\hline Hypertension & 0.081 & 0.020 & 0.086 & $<0.001$ & 0.086 & $<0.001$ & & \\
\hline Dyslipidemia & -0.008 & 0.804 & & & -0.021 & 0.387 & & \\
\hline Diabetes & 0.019 & 0.566 & & & 0.015 & 0.490 & & \\
\hline Sleep time & -0.019 & 0.564 & & & 0.020 & 0.375 & & \\
\hline Alcohol & 0.124 & $<0.001$ & 0.124 & $<0.001$ & 0.098 & $<0.001$ & 0.110 & $<0.001$ \\
\hline $\begin{array}{l}\text { Brinkman } \\
\text { index }\end{array}$ & 0.028 & 0.419 & & & 0.010 & 0.676 & & \\
\hline METs & -0.045 & 0.160 & & & -0.062 & 0.005 & & \\
\hline BMI & -0.058 & 0.349 & & & 0.048 & 0.340 & & \\
\hline BFM & 0.080 & 0.381 & & & -0.039 & 0.608 & 0.181 & $<0.001$ \\
\hline SMM & -0.052 & 0.533 & & & -0.061 & 0.262 & & \\
\hline VAT & 0.130 & 0.326 & 0.184 & $<0.001$ & 0.173 & 0.003 & 0.203 & $<0.001$ \\
\hline SAT & 0.009 & 0.936 & & & 0.138 & 0.016 & & \\
\hline VAT/SAT ratio & 0.011 & 0.902 & & & -0.027 & 0.551 & & \\
\hline
\end{tabular}

Note: beta standardized regression coefficients.

\section{Discussion}

The main findings of the present study can be summarized as follows. There were proven sex-based differences in the MR-proADM levels. MR-proADM was significantly related to all anthropometric indices (BMI, VAT, SAT, VAT/SAT ratio, BFM, and SMM) in men and women. Independent of age, anamnesis, and lifestyle factors, MR-proADM was significantly associated with VAT from a stepwise forward selection method. However, BMI, SAT, and VAT/SAT ratio showed no significant association with MR-proADM in both sexes. In general, studies show that fat distribution, and not fat deposit, is the key factor explaining the obesity paradox [6]. Some studies have suggested that the VAT is more strongly associated with metabolic and cardiovascular risk than SAT [22-24]. These results indicated that the plasma MR-proADM concentration was representative of fat distribution. 
In general, men have larger amounts of VAT than women, whereas women have more subcutaneous fat areas [25-27]. In Table 1, the means of VAT and BFM differed significantly by sex. MR-proADM was associated with BFM, but not with SAT and VAT/SAT ratio in women. These results may indicate that increased BFM signified increased VAT in women. These sex-based differences in MR-proADM were predicted to indicate the difference in the amount of VAT accumulation.

Adipokines influence several important systemic phenomena: energy metabolism, inflammation, cancer, and infectious disease. In the process, they interact with a large number of different organ systems, vasculature, muscle, reproduction, and liver [28]; ADM is also known as an adipokine [11]. Previous reports indicate that ADM expression significantly increased obesity compared to the control group. In addition, elevated plasma ADM levels corresponded with increased body weight in animal models [29] and human studies [30]. BMI correlated with MR-proADM not only in lean participants, but also in obese patients with no additional medical problems [14]. From the prospective of weight loss, the decrease in high sensitive C-reactive protein levels during weight loss was an independent determinant of changes in plasma MR-proADM concentrations [31,32]. MR-proADM correlated with a reduction in BFM, indicating a reduced release into the circulation from adipocytes [11]. We examined the biological function of VAT among the adipocytes to explain the results of this study. Whereas many inflammatory markers were similarly associated with SAT and VAT, some inflammatory markers were more strongly associated with VAT than with SAT [33]. Some studies confirm that VAT is a major source of secreted ADM [13,14]. The increase in ADM levels found in the case of low-grade inflammation in VAT associated with obesity may be a counter-regulatory (compensatory) mechanism for inflammatory cytokines [34,35]. However, the contribution of VAT to inflammation may not be completely accounted for by clinical measures of BMI [33]. Although BMI is widely used, it does not accurately measure fat content, reflect proportions of muscle and fat, or account for sex and ethnic differences in fat content and the distribution of visceral and subcutaneous fat [36]. Thus, BMI cannot accurately reflect fat distribution. Furthermore, VAT may be a critical factor of inflammation that is not completely accounted for by BMI and waist circumference [33]. Normal weight evaluated by BMI may mask metabolically healthy or unhealthy conditions, contributing to the obesity paradox, because VAT accumulation was not determined. To our knowledge, this study is the first to report that MR-proADM is significantly associated with VAT, not BMI. Based on the pleiotropic effects of the ADM signal $[9,37,38]$, changes in circulating levels of MR-proADM could possibly reflect changes in body composition, endocrine, and metabolic milieu.

The limitations of our study include its cross-sectional design. In a follow-up survey, we plan to assess the participants by accessing actual medical records; therefore, we expect that these additional data will lead to further detailed analysis of cardiometabolic disease. The strength of the current study is that many participants were included, and we implemented a population-based cohort design.

\section{Conclusions}

Our results suggest that plasma MR-proADM concentration is a more reliable indicator of VAT for fat distribution, and thus, MR-proADM may help better understand the obesity paradox.

Author Contributions: Conceptualization, T.K.; methodology, T.K. and N.K.; formal analysis, T.K.; investigation, T.K. and N.K.; data curation, T.K.; writing-original draft preparation, T.K.; supervision, R.U.; project administration, T.K. and N.K.; funding acquisition, T.K. and R.U. All authors have read and agreed to the published version of the manuscript.

Acknowledgments: This study was supported by Takeda Science Foundation, Kondou Kinen Medical Foundation, Grant-in-Aid for Scientific Research on Priority Areas of Cancer (No. 17015018) and Innovative Areas (No. 221S0001), and by JSPS KAKENHI Grant Numbers 15K19185, 16H06277, and 18K17387 from the Japanese Ministry of Education, Culture, Sports, Science and Technology.

Conflicts of Interest: There are no conflicts of interest. 


\section{References}

1. Velasquez-Rodriguez, C.M.; Velasquez-Villa, M.; Gomez-Ocampo, L.; Bermudez-Cardona, J. Abdominal obesity and low physical activity are associated with insulin resistance in overweight adolescents: a cross-sectional study. BMC Pediatrics 2014, 14, 258. [CrossRef]

2. Pal, S.; Radavelli-Bagatini, S. Association of arterial stiffness with obesity in Australian women: a pilot study. J. Clin. Hypertens. (Greenwich) 2013, 15, 118-123. [CrossRef] [PubMed]

3. Abbasi, A.; Juszczyk, D.; van Jaarsveld, C.H.M.; Gulliford, M.C. Body Mass Index and Incident Type 1 and Type 2 Diabetes in Children and Young Adults: A Retrospective Cohort Study. J. Endocr. Soc. 2017, 1, 524-537. [CrossRef] [PubMed]

4. Chooi, Y.C.; Ding, C.; Magkos, F. The epidemiology of obesity. Metabolism 2019, 92, 6-10. [CrossRef] [PubMed]

5. Wildman, R.P.; Muntner, P.; Reynolds, K.; McGinn, A.P.; Rajpathak, S.; Wylie-Rosett, J.; Sowers, M.R. The obese without cardiometabolic risk factor clustering and the normal weight with cardiometabolic risk factor clustering: prevalence and correlates of 2 phenotypes among the US population (NHANES 1999-2004). Arch. Intern. Med. 2008, 168, 1617-1624. [CrossRef]

6. Ahima, R.S.; Lazar, M.A. Physiology. The health risk of obesity-better metrics imperative. Science 2013, 341, 856-858. [CrossRef]

7. Bosello, O.; Vanzo, A. Obesity paradox and aging. Eat. Weight Disord. 2019. [CrossRef]

8. Kitamura, K.; Kangawa, K.; Kawamoto, M.; Ichiki, Y.; Nakamura, S.; Matsuo, H.; Eto, T. Adrenomedullin: A novel hypotensive peptide isolated from human pheochromocytoma. Biochem. Biophys. Res. Commun. 1993, 192, 553-560. [CrossRef] [PubMed]

9. Koyama, T.; Sakurai, T.; Kamiyoshi, A.; Ichikawa-Shindo, Y.; Kawate, H.; Shindo, T. Adrenomedullin-RAMP2 System in Vascular Endothelial Cells. J. Atheroscler. Thromb. 2015, 22, 647-653. [CrossRef]

10. Cheung, B.M.; Tang, F. Adrenomedullin: Exciting new horizons. Recent Pat. Endocr. Metab. Immune Drug Discov. 2012, 6, 4-17. [CrossRef] [PubMed]

11. Li, Y.; Jiang, C.; Wang, X.; Zhang, Y.; Shibahara, S.; Takahashi, K. Adrenomedullin is a novel adipokine: Adrenomedullin in adipocytes and adipose tissues. Peptides 2007, 28, 1129-1143. [CrossRef] [PubMed]

12. Paulmyer-Lacroix, O.; Desbriere, R.; Poggi, M.; Achard, V.; Alessi, M.C.; Boudouresque, F.; Ouafik, L.; Vuaroqueaux, V.; Labuhn, M.; Dutourand, A.; et al. Expression of adrenomedullin in adipose tissue of lean and obese women. Eur. J. Endocrinol. 2006, 155, 177-185. [CrossRef] [PubMed]

13. Del Ry, S.; Cabiati, M.; Bianchi, V.; Caponi, L.; Di Cecco, P.; Marchi, B.; Randazzo, E.; Caselli, C.; Prescimone, T.; Clerico, A.; et al. Mid-regional-pro-adrenomedullin plasma levels are increased in obese adolescents. Eur. J. Nutr. 2016, 55, 1255-1260. [CrossRef] [PubMed]

14. Vila, G.; Riedl, M.; Maier, C.; Struck, J.; Morgenthaler, N.G.; Handisurya, A.; Prager, G.; Ludvik, B.; Clodi, M.; Luger, A. Plasma MR-proADM correlates to BMI and decreases in relation to leptin after gastric bypass surgery. Obesity 2009, 17, 1184-1188. [CrossRef] [PubMed]

15. Ohlsson, T.; Nilsson, P.M.; Persson, M.; Melander, O. Midregional proadrenomedullin predicts reduced blood pressure and glucose elevation over time despite enhanced progression of obesity markers. J. Hypertens. 2019, 37, 590-595. [CrossRef] [PubMed]

16. Meeran, K.; O'Shea, D.; Upton, P.D.; Small, C.J.; Ghatei, M.A.; Byfield, P.H.; Bloom, S.R. Circulating adrenomedullin does not regulate systemic blood pressure but increases plasma prolactin after intravenous infusion in humans: A pharmacokinetic study. J. Clin. Endocrinol. Metab. 1997, 82, 95-100. [CrossRef]

17. Caruhel, P.; Mazier, C.; Kunde, J.; Morgenthaler, N.G.; Darbouret, B. Homogeneous time-resolved fluoroimmunoassay for the measurement of midregional proadrenomedullin in plasma on the fully automated system B.R.A.H.M.S KRYPTOR. Clin. Biochem. 2009, 42, 725-728. [CrossRef]

18. Wakai, K.; Hamajima, N.; Okada, R.; Naito, M.; Morita, E.; Hishida, A.; Kawai, S.; Nishio, K.; Yin, G.; Asai, Y.; et al. Profile of Participants and Genotype Distributions of 108 Polymorphisms in a Cross-Sectional Study of Associations of Genotypes With Lifestyle and Clinical Factors: A Project in the Japan Multi-Institutional Collaborative Cohort (J-MICC) Study. J. Epidemiol. 2011, 21, 223-235. [CrossRef]

19. Haraguchi, N.; Koyama, T.; Kuriyama, N.; Ozaki, E.; Matsui, D.; Watanabe, I.; Uehara, R.; Watanabe, Y. Assessment of anthropometric indices other than BMI to evaluate arterial stiffness. Hypertens. Res. 2019, 42, 1599-1605. [CrossRef] 
20. Hara, M.; Higaki, Y.; Taguchi, N.; Shinchi, K.; Morita, E.; Naito, M.; Hamajima, N.; Takashima, N.; Suzuki, S.; Nakamura, A.; et al. Effect of the PPARG2 Pro12Ala polymorphism and clinical risk factors for diabetes mellitus on $\mathrm{HbA} 1 \mathrm{c}$ in the Japanese general population. J. Epidemiol. 2012, 22, 523-531. [CrossRef]

21. Oshima, Y.; Shiga, T.; Namba, H.; Kuno, S. Estimation of whole-body skeletal muscle mass by bioelectrical impedance analysis in the standing position. Obes. Res. Clin. Pract. 2010, 4, e1-e7. [CrossRef]

22. Fox, C.S.; Massaro, J.M.; Hoffmann, U.; Pou, K.M.; Maurovich-Horvat, P.; Liu, C.Y.; Vasan, R.S.; Murabito, J.M.; Meigs, J.B.; Cupples, L.A.; et al. Abdominal visceral and subcutaneous adipose tissue compartments: Association with metabolic risk factors in the Framingham Heart Study. Circulation 2007, 116, $39-48$. [CrossRef] [PubMed]

23. Bouchi, R.; Takeuchi, T.; Akihisa, M.; Ohara, N.; Nakano, Y.; Nishitani, R.; Murakami, M.; Fukuda, T.; Fujita, M.; Minami, I.; et al. High visceral fat with low subcutaneous fat accumulation as a determinant of atherosclerosis in patients with type 2 diabetes. Cardiovasc. Diabetol. 2015, 14, 136. [CrossRef]

24. Kaess, B.M.; Pedley, A.; Massaro, J.M.; Murabito, J.; Hoffmann, U.; Fox, C.S. The ratio of visceral to subcutaneous fat, a metric of body fat distribution, is a unique correlate of cardiometabolic risk. Diabetologia 2012, 55, 2622-2630. [CrossRef] [PubMed]

25. Enzi, G.; Gasparo, M.; Biondetti, P.R.; Fiore, D.; Semisa, M.; Zurlo, F. Subcutaneous and visceral fat distribution according to sex, age, and overweight, evaluated by computed tomography. Am. J. Clin. Nutr. 1986, 44, 739-746. [CrossRef] [PubMed]

26. Geer, E.B.; Shen, W. Gender differences in insulin resistance, body composition, and energy balance. Gend. Med. 2009, 6 (Suppl. 1), 60-75. [CrossRef]

27. van den Munckhof, I.C.L.; Holewijn, S.; de Graaf, J.; Rutten, J.H.W. Sex differences in fat distribution influence the association between BMI and arterial stiffness. J. Hypertens. 2017, 35, 1219-1225. [CrossRef]

28. Trujillo, M.E.; Scherer, P.E. Adipose tissue-derived factors: Impact on health and disease. Endocr. Rev. 2006, 27, 762-778. [CrossRef]

29. Nambu, T.; Arai, H.; Komatsu, Y.; Yasoda, A.; Moriyama, K.; Kanamoto, N.; Itoh, H.; Nakao, K. Expression of the adrenomedullin gene in adipose tissue. Regul. Pept. 2005, 132, 17-22. [CrossRef]

30. Kawano, S.; Kawagoe, Y.; Kuwasako, K.; Shimamoto, S.; Igarashi, K.; Tokashiki, M.; Kitamura, K.; Kato, J. Gender-related alterations in plasma adrenomedullin level and its correlation with body weight gain. Endocr. Connect. 2015, 4, 43-49. [CrossRef]

31. Lim, S.C.; Morgenthaler, N.G.; Subramaniam, T.; Wu, Y.S.; Goh, S.K.; Sum, C.F. The relationship between adrenomedullin, metabolic factors, and vascular function in individuals with type 2 diabetes. Diabetes Care 2007, 30, 1513-1519. [CrossRef] [PubMed]

32. Kistorp, C.; Bliddal, H.; Goetze, J.P.; Christensen, R.; Faber, J. Cardiac natriuretic peptides in plasma increase after dietary induced weight loss in obesity. BMC Obes. 2014, 1, 24. [CrossRef] [PubMed]

33. Pou, K.M.; Massaro, J.M.; Hoffmann, U.; Vasan, R.S.; Maurovich-Horvat, P.; Larson, M.G.; Keaney, J.F., Jr.; Meigs, J.B.; Lipinska, I.; Kathiresan, S.; et al. Visceral and subcutaneous adipose tissue volumes are cross-sectionally related to markers of inflammation and oxidative stress: The Framingham Heart Study. Circulation 2007, 116, 1234-1241. [CrossRef] [PubMed]

34. Dandona, P.; Aljada, A.; Bandyopadhyay, A. Inflammation: The link between insulin resistance, obesity and diabetes. Trends Immunol. 2004, 25, 4-7. [CrossRef]

35. Kato, J.; Kitamura, K. Bench-to-bedside pharmacology of adrenomedullin. Eur. J. Pharmacol. 2015, 764, 140-148. [CrossRef]

36. Krakauer, N.Y.; Krakauer, J.C. A new body shape index predicts mortality hazard independently of body mass index. PLoS ONE 2012, 7, e39504. [CrossRef] 
37. Koyama, T.; Ochoa-Callejero, L.; Sakurai, T.; Kamiyoshi, A.; Ichikawa-Shindo, Y.; Iinuma, N.; Arai, T.; Yoshizawa, T.; Iesato, Y.; Lei, Y.; et al. Vascular endothelial adrenomedullin-RAMP2 system is essential for vascular integrity and organ homeostasis. Circulation 2013, 127, 842-853. [CrossRef]

38. Koyama, T.; Kuriyama, N.; Ozaki, E.; Matsui, D.; Watanabe, I.; Takeshita, W.; Iwai, K.; Watanabe, Y.; Nakatochi, M.; Shimanoe, C.; et al. Genetic Variants of RAMP2 and CLR are Associated with Stroke. J. Atheroscler. Thromb. 2017, 24, 1267-1281. [CrossRef]

(C) 2020 by the authors. Licensee MDPI, Basel, Switzerland. This article is an open access article distributed under the terms and conditions of the Creative Commons Attribution (CC BY) license (http://creativecommons.org/licenses/by/4.0/). 